\title{
Tympanojugular Paragangliomas: Surgical Management and Clinicopathological Features
}

\author{
Sampath Chandra Prasad ${ }^{1} \bullet$ Carlo Terenzio Paties ${ }^{2} \bullet$ Francesca Schiavi $^{3} \bullet$ \\ Diana Liberata Esposito ${ }^{4}$ - Lavinia Vittoria Lotti ${ }^{5} \bullet$ Renato Mariani- \\ Costantini $^{4} \bullet$ Mario Sanna ${ }^{1}$ \\ ${ }^{1}$ Otology and Skull Base Unit, Gruppo Otologico Piacenza, Piacenza, Italy; ${ }^{2}$ Department of \\ Oncology-Hematology, Service of Anatomic Pathology, Guglielmo da Saliceto Hospital, \\ Piacenza, Italy; ${ }^{3}$ Familial Cancer Clinic and Oncoendocrinology, Veneto Institute of \\ Oncology, IRCCS, Padua, Italy; ${ }^{4}$ Center of Aging Science and Translational Medicine \\ (CeSI-MeT) and Department of Medical, Oral and Biotechnological Sciences, Gabriele \\ d'Annunzio University, Chieti, Italy; ${ }^{5}$ Department of Experimental Medicine, Sapienza \\ University of Rome, Rome, Italy
}

Author for correspondence: Renato Mariani-Costantini, Center of Aging Science and Translational Medicine (CeSI-MeT), "Gabriele d'Annunzio" University, Via Luigi Polacchi 11,66100 Chieti, Italy. E-mail:rmc@unich.it

Doi: http://dx.doi.org/10.15586/paraganglioma.2019.ch6

\begin{abstract}
In this chapter, we provide a focused review on a highly challenging subset of head and neck paragangliomas, that is, those arising from the skull base (jugulotympanic region). Presently, these tumors can be cured only with surgery, which must be performed in highly specialized skull base surgical centers. We review here the clinical presentation, diagnostic workup, classification, and surgical management of these rare but important tumors, together with currently available evidence concerning genetics, developmental origin, and pathology.
\end{abstract}

Keywords: Angiography; High-resolution computed tomography; Infratemporal fossa approach; Modified Fisch classification; Tympanojugular paraganglioma

In: Paraganglioma: A Multidisciplinary Approach. Renato Mariani-Costantini (Editor), Codon Publications, Brisbane, Australia. ISBN: 978-0-9944381-7-1; Doi: http://dx.doi.org/10.15586/ paraganglioma.2019

Copyright: The Authors.

Licence: This open access article is licenced under Creative Commons Attribution 4.0 International (CC BY 4.0). https://creativecommons.org/licenses/by-nc/4.0/ 


\section{INTRODUCTION}

Paragangliomas of the head and neck can be classified as temporal bone paragangliomas (TBP) (tympanomastoid and tympanojugular paragangliomas [TJPs]) and neck paragangliomas (vagal and carotid body paragangliomas) according to their presentation (1). Indeed, paragangliomas can arise from more than 20 locations in the head and neck, but they are very rare in other sites. Tympanomastoid paragangliomas arise within the inferior tympanic or mastoid canaliculi, while TJPs arise from the paraganglia of the adventitia of the jugular bulb (JB).

TJPs present a challenge for the treating physician because of the fact that these tumors are vascular, locally aggressive, and involve important neurovascular structures, like the internal carotid artery (ICA), the JB, the facial nerve (FN) and the lower cranial nerves (LCNs, CN IX, X, XI, XII). Because of their slow and silent growth, there is often a delayed presentation, with cranio-temporo-cervical extensions that, in the past, left them inoperable. However, many developments in the past decades have changed this situation. Various rational approaches have been described to access different parts of the skull base after a thorough understanding of the anatomical and surgical characteristics, making it easy and safe to remove tumors in the area. This has also been aided by technical advances in microsurgery, neuromonitoring, neuroanesthesia, and neuroradiology. All this has resulted in surgery having emerged as the mainstay of treatment for TJPs. According to the Fisch classification of TBPs, TJPs are traditionally classified into classes A, B, C, and D based on the location and extension assessed by highresolution computed tomography (HRCT). This was subsequently modified by Sanna (2) to include sub-classifications and an additional class V, comprising tumors that involve the vertebral artery (VA) (Table 1).

\section{CLINICAL PRESENTATIONS}

A pulsatile middle ear mass is pathognomonic of a temporal bone paraganglioma $(3,4,5,6)$. The classically described blanching of the middle ear component, that is, Brown's sign, is present in $20 \%$ of the cases (6). Otoscopy alone is not reliable to assess the extent, most significantly related to the degree of hypotympanic extension (6). TBPs invading the tympanic bone from the jugular fossa may show what is called the "rising sun" sign. Paragangliomas can also extend through the tympanic membrane and be confused with an inflammatory polyp. Occasionally, otorrhagia can be a significant clinical symptom.

The most common presenting symptom of a TJP is that of hearing loss, present in approximately $60-80 \%$ of the cases, with pulsatile tinnitus also affecting the majority of the patients (60-80\%) (3, 6-26). Hearing loss is usually conductive because the tumor compresses or erodes the ossicular chain, or due to effusion. Given the slow growth and the nonspecific nature of the symptoms, patients present with an average of 2-3 years delay after the onset of the symptoms.

When the inner ear is invaded, there can be sensorineural hearing loss or vestibular symptoms. Lower cranial nerve deficits usually develop secondary to invasion of the medial wall of the jugular fossa. Cranial nerve deficits can be 


\section{TABLE 1 Modified Fisch classification of temporal bone paragangliomas (TBPs)}

\begin{tabular}{|c|c|c|}
\hline \multirow{7}{*}{$\begin{array}{l}\text { Tympanomastoid } \\
\text { paragangliomas } \\
\text { (TMPs) }\end{array}$} & \multirow[t]{3}{*}{ Class A } & Tumors confined to the middle ear \\
\hline & & Tumor margins clearly visible on otoscopic examination \\
\hline & & $\begin{array}{l}\text { Tumor margins not visible on otoscopy. Tumors may extend } \\
\text { anteriorly to the Eustachian tube and/or to the posterior } \\
\text { mesotympanum }\end{array}$ \\
\hline & Class B & $\begin{array}{l}\text { Tumors confined to the tympanomastoid cavity without destruction } \\
\text { of bone in the infralabyrinthine compartment of the temporal bone }\end{array}$ \\
\hline & & $\begin{array}{l}\text { Tumors involving the middle ear with extension to the } \\
\text { hypotympanum }\end{array}$ \\
\hline & & $\begin{array}{l}\text { Tumors involving the middle ear with extension to the } \\
\text { hypotympanum and the mastoid }\end{array}$ \\
\hline & & $\begin{array}{l}\text { Tumors confined to the tympanomastoid compartment with } \\
\text { erosion of the carotid canal }\end{array}$ \\
\hline \multirow[t]{14}{*}{$\begin{array}{l}\text { Tympanojugular } \\
\text { paragangliomas } \\
\text { (TJPs) }\end{array}$} & Class C & $\begin{array}{l}\text { Tumors extending beyond the tympanomastoid cavity, destroying } \\
\text { bone of the infralabyrinthine and apical compartment of the temporal } \\
\text { bone and involving the carotid canal }\end{array}$ \\
\hline & & $\begin{array}{l}\text { Cl Tumors with limited involvement of the vertical portion of the } \\
\text { carotid canal }\end{array}$ \\
\hline & & C2 Tumors invading the vertical portion of the carotid canal \\
\hline & & $\begin{array}{l}\text { C3 Tumors with invasion of the horizontal portion of the carotid } \\
\text { canal }\end{array}$ \\
\hline & & C4 Tumors reaching the anterior foramen lacerum \\
\hline & Class D & Tumors with intracranial extension \\
\hline & & Del Tumors up to $2 \mathrm{~cm}$ dural displacement \\
\hline & & De2 Tumors with more than $2 \mathrm{~cm}$ dural displacement \\
\hline & & Dil Tumors up to $2 \mathrm{~cm}$ intradural extension \\
\hline & & Di2 Tumors with more than $2 \mathrm{~cm}$ intradural extension \\
\hline & & Di3 Tumors with inoperable intradural extension \\
\hline & Class V & Tumors involving the VA \\
\hline & & Tumors involving the extradural VA \\
\hline & & Tumors involving the intradural VA \\
\hline
\end{tabular}

masked, due to slow progression, aided by gradual compensation from the contralateral nerves. In approximately $10 \%$ of the cases, cranial nerve palsies can be silent. Palsies of cranial nerves IX and X are seen in approximately 35-40\% of the cases, and those of cranial nerves XI and XII are seen in about $21-30 \%$ of cases. Involvement of the FN is reported in 10-39\% of the cases (3, 8, 25-29).

A jugular fossa pathology must be kept in mind for patients presenting with isolated or multiple LCN palsies. Vocal fold paralysis, presenting with a change in voice, is the most common clinical scenario (30). Palatal asymmetry strongly 
suggests a skull base pathology involving the glossopharyngeal or vagus nerves. Complete cranial nerves examination, including palpation of the neck and upper aero-digestive tract endoscopy, is an integral part of the examination for TBPs.

\section{DIAGNOSTIC WORKUP}

The study of axial and coronal HRCTs is mandatory for the diagnosis of TJPs. When the jugular foramen is involved, T1, T2, and T1 with gadoliniumenhanced sequences, MR angiography and venography are necessary (31). A 4-vessel angiography is reserved for difficult cases with ICA and VA involvement. Since TJPs cannot be biopsied due to their vascularity, the diagnosis is based solely on radiology. Hence, it is important to identify and diagnose the pathologies by radiology, which in turn influences management options, surgical approach, and prognosis (31).

\section{High-resolution computed tomography}

The bone erosion seen on high-resolution CT scans of TJPs is classically described as a "moth eaten" appearance. The margins of the jugular fossa may be irregular and expanded, with evidence of erosion of the caroticojugular crest or jugular spine. In advanced cases, the entire jugular foramen may be destroyed. However, it is very important to differentiate tympano-mastoid paragangliomas from TJP by identifying the margins of the jugular foramen. If the jugular foramen is found to be by and large free of tumor or anatomical distortion, it is most likely to be a tympanomastoid paraganglioma. Magnetic resonance imaging (MRI) can be done then to distinguish the two entities (6).

\section{Magnetic resonance imaging}

MRI is very useful in mapping TJP. It provides information about the extent of the tumor, both into the neck and intracranially. The incidence of intracranial extension in TJPs is about $60-75 \%$ and the rate of intradural involvement is approximately $30 \%(3,8,32,33)$. Paragangliomas show low to intermediate intensity in T1 signal and high intensity in T2 signal. A classic "salt and pepper" pattern appearance can be seen in lesions $>2 \mathrm{~cm}$, especially in T2 images. This is due to areas of hyperintensity on T2 images because of slow flow within the tumor and the presence of intratumoral vasculature appearing as flow voids (31, $34,35)$. Dural invasion is difficult to detect due to the fact that the dura is often pushed medially rather truly infiltrated. MRI also gives information regarding invasion into the marrow spaces of the skull base, with obliteration of the normal fatty signal. Along with T1, T2, and contrast studies, other sequences used to study paragangliomas are dual T2 fast spin echo sequences, non-contrast and contrast time of flight sequences, as well as contrast magnetic resonance angiography (MRA) and venography (MRV) along with three-dimensional (3D) reconstructions (36). 


\section{Angiography}

Angiography is important both for the diagnosis and for the management of TJPs. Paragangliomas demonstrate a characteristic blush and rapid venous diffusion. Angiography also demonstrates the vascular supply of the tumor, the degree of ICA involvement, the contralateral cerebral blood flow, the venous drainage, and aids in pre-operative embolization in case of surgery.

\section{CHOOSING THE RIGHT APPROACH FOR THE JUGULAR FOSSA}

The jugular foramen is a very complex area closely encompassing critical neurovascular structures. The most important goal with surgeries in this area is to achieve optimal exposure of the structures while minimizing the damage and to obtain proximal and distal exposures of the important arteries and veins $(13,37,38)$. The two essential facts to be considered while obtaining adequate surgical exposure are (i) whether the FN needs to be mobilized and (ii) whether the middle ear can be preserved. The next most important aspect is the degree of ICA involvement, followed by the extent of intracranial extension.

The infratemporal fossa approach (ITFA) type A is the workhorse of TJP surgery ever since it was first described by Fisch and Pillsbury in 1979 (39). ITFA-A allows access to the jugular foramen, the infralabyrinthine areas, the apical compartments of the petrous bone, and the vertical segment of the internal carotid artery (Figure 1A). The key feature in this approach is the anterior transposition of the FN, which opens up the above-mentioned areas for dissection (Figure 1B). The other structures that prevent lateral access to these areas include the tympanic bone, the digastric muscle, and the styloid process (Figure $1 \mathrm{C}$ ), which are removed to obtain unhindered access. The morbidity with ITFA-A includes conductive hearing loss, temporary or permanent dysfunction of the FN, and temporary masticatory problems.

\section{SURGICAL STEPS}

A postauricular skin incision is performed. A small, anteriorly based musculoperiosteal flap is elevated to help in closure afterward. The external auditory canal is transected as before. The FN is identified at its exit from the temporal bone. The main trunk is found at the perpendicular bisection of a line joining the cartilaginous pointer to the mastoid tip. The main trunk is traced in the parotid until the proximal parts of the temporal and zygomatic branches are identified. The posterior belly of the digastric muscle and the sternocleidomastoid muscle are divided close to their origin. The internal jugular vein and the external and internal carotid arteries are identified in the neck. The vessels are marked with umbilical tape. The skin of the external auditory canal, the tympanic membrane, the malleus, and the incus are removed. A canal wall-down mastoidectomy is 

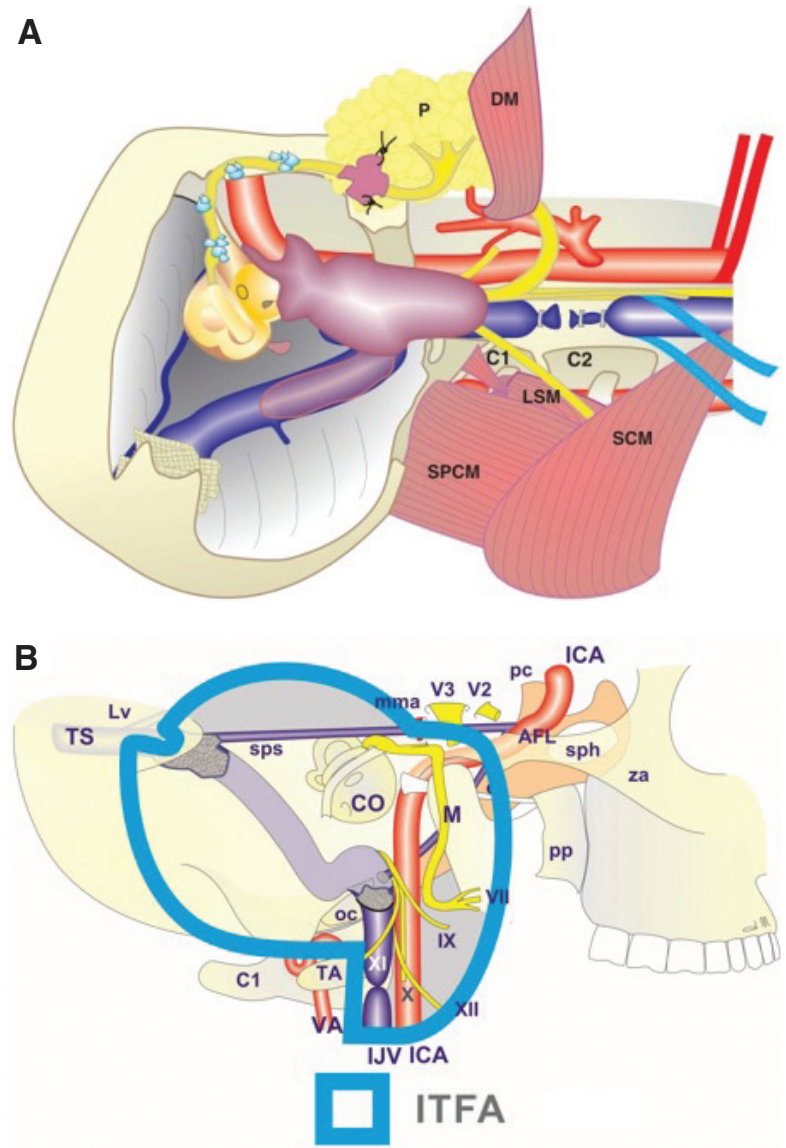

Figure 1 Illustrations for ITFA type A. (A) surgical view in ITFA, (B) surgical limit in ITFA, and (C) obstacles to approach the jugular bulb.

C1, atlas; C2, axis; Ch, cochlea; $\mathrm{CO}$, cochlea; DM, posterior belly of the digastric muscle; ev, emissary vein; Involvement of the facial nerve (FN); ICA,

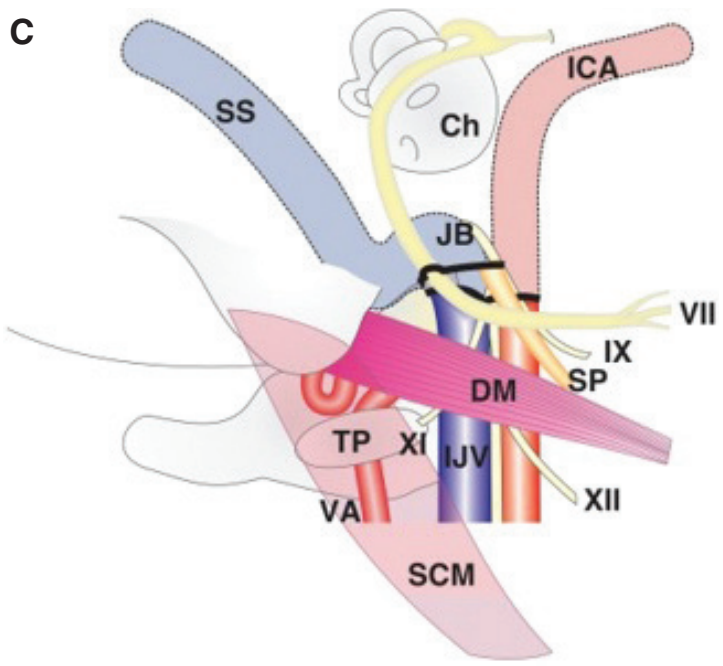
internal carotid artery; IJV, internal jugular vein; IX, glossopharyngeal nerve; JB, jugular bulb; LSM, levator scapulae muscle; Lv, vein of Labbe; OC, occipital condyle; $\mathrm{P}$, parotid gland; $\mathrm{pc}$, clinoid process; pp, pterygoid plate; M, mandible; SCM, sternocleidomastoid muscle; SP, styloid process; SPCM, splenius capitis muscle; sph, sphenoid sinus; za, zygomatic arch; sps, superior petrosal sinus; TA, transverse process of atlas; TP, transverse process of the atlas; TS, transverse sinus; V2, maxillary branch of trigeminal nerve; V3, mandibular branch of trigeminal nerve; VA, vertebral artery; VII, facial nerve; XI, spinal accessory nerve; XII, hypoglossal nerve. 
performed, with removal of the bone anterior and posterior to the sigmoid sinus. The FN is skeletonized from the stylomastoid foramen to the geniculate ganglion. The last shell of bone is removed using a double-curved raspatory. The suprastructure of the stapes is preferably removed after cutting its crura with microscissors. The inferior tympanic bone is widely removed, and the mastoid tip is amputated using a rongeur. A new fallopian canal (arrow) is drilled in the root of the zygoma superior to the Eustachian tube. The FN is freed at the level of the stylomastoid foramen using strong scissors. The soft tissues at this level are not separated from the nerve. The mastoid segment is next elevated using a Beaver knife to cut the fibrous attachments between the nerve and the fallopian canal. The tympanic segment of the nerve is carefully elevated, using a curved raspatory, until the level of the geniculate ganglion is reached. A non-toothed forceps is used to hold the soft tissue surrounding the nerve at the stylomastoid foramen, and anterior rerouting is carried out. A tunnel is created in the parotid gland to lodge the transposed nerve. The tunnel is closed around the nerve using two sutures. A closer view shows the FN in its new bony canal, just superior to the Eustachian tube. The nerve is fixed to the new bony canal using fibrin glue. Drilling of the infralabyrinthine cells is completed, and the vertical portion of the internal carotid artery is identified. The mandibular condyle is separated from the anterior wall of the external auditory canal using a large septal raspatory. The Fisch infratemporal fossa retractor is applied, and the mandibular condyle is anteriorly displaced, with care being taken not to injure the FN. The anterior wall of the external auditory canal is further drilled, thus completing the exposure of the vertical portion of the internal carotid artery. A small incision is made in the posterior fossa dura just behind the sigmoid sinus, through which an aneurysm needle is passed. Another incision is made just anterior to the sinus to allow for the exit of the needle. The sinus is closed by double ligation with a Vicryl suture. Suture closure of the sinus, however, may lead to gaps in the dural incision, with a higher risk of cerebrospinal fluid leakage postoperatively. Alternatively, the sigmoid sinus can be closed with Surgicel extraluminal packing. The structures attached to the styloid process are severed. The styloid is fractured using a rongeur and is then cut with strong scissors. The remaining tough fibrous tissue surrounding the internal carotid artery at its ingress into the skull base is carefully removed using scissors. The internal jugular vein in the neck is double ligated and cut or closed with vascular clips (easier and faster method). The vein is elevated superiorly, with care being taken not to injure the related LCNs. In cases in which the 11th nerve passes laterally, the vein has to be pulled under the nerve carefully to prevent it from being damaged. If necessary (as in the case of TJPs), the lateral wall of the sigmoid sinus can be removed. Removal continues down to the level of the JB. The lateral wall of the JB is opened. Bleeding usually occurs from the apertures of the inferior petrosal sinus and the condylar emissary vein. This is controlled by Surgicel packing. If there is limited intradural extension, the dura is opened without injury to the endolymphatic sac. At the end of the procedure, the Eustachian tube is closed by a piece of muscle. The dural opening is closed by a muscle plug or with only abdominal fat. We never use a rotated temporalis muscle (as suggested by Fisch) in order to avoid esthetic problems but the sternocleidomastoid muscle and the digastric muscle are sutured together and the temporalis muscle is left in its place. 


\section{EXTENSIONS OF THE INFRATEMPORAL FOSSA TYPE A APPROACH (ITFA-A)}

Based on the ITFA-A approach, various extensions can be added depending on the extent of the pathology. The standard extension we use is a transcondylartranstubercular extension for C2-C4 tumors (Figures 2 and 3). This allows additional posteroinferior and medial access to the jugular fossa, widening the exposure, thus facilitating venous and neural control. The widened angle also affords better access to the petrous apex, medial to the carotid artery. Very rarely, a far lateral is employed with full exposure of the vertebral artery. The use of a translabyrinthine extension is occasionally required for otic capsule involvement. A modified transcochlear approach is uncommonly required to access petrous apex, clival involvement, and infratemporal fossa involvement.

\section{TRANSCONDYLAR-TRANSTUBERCULAR EXTENSION OF THE ITFA-A}

The classic ITFA-A of Fisch permits only superior and anterior exposure of the JB and is indicated for class C1 and certain C2 tumors. For larger tumors, such as classes C2-C4 tumors involving the LCNs, a transcondylar-transtubercular extension is required in addition to the classic ITFA-A. This extension facilitates inferomedial access to the JB above the lateral mass of the atlas and occipital condyle.

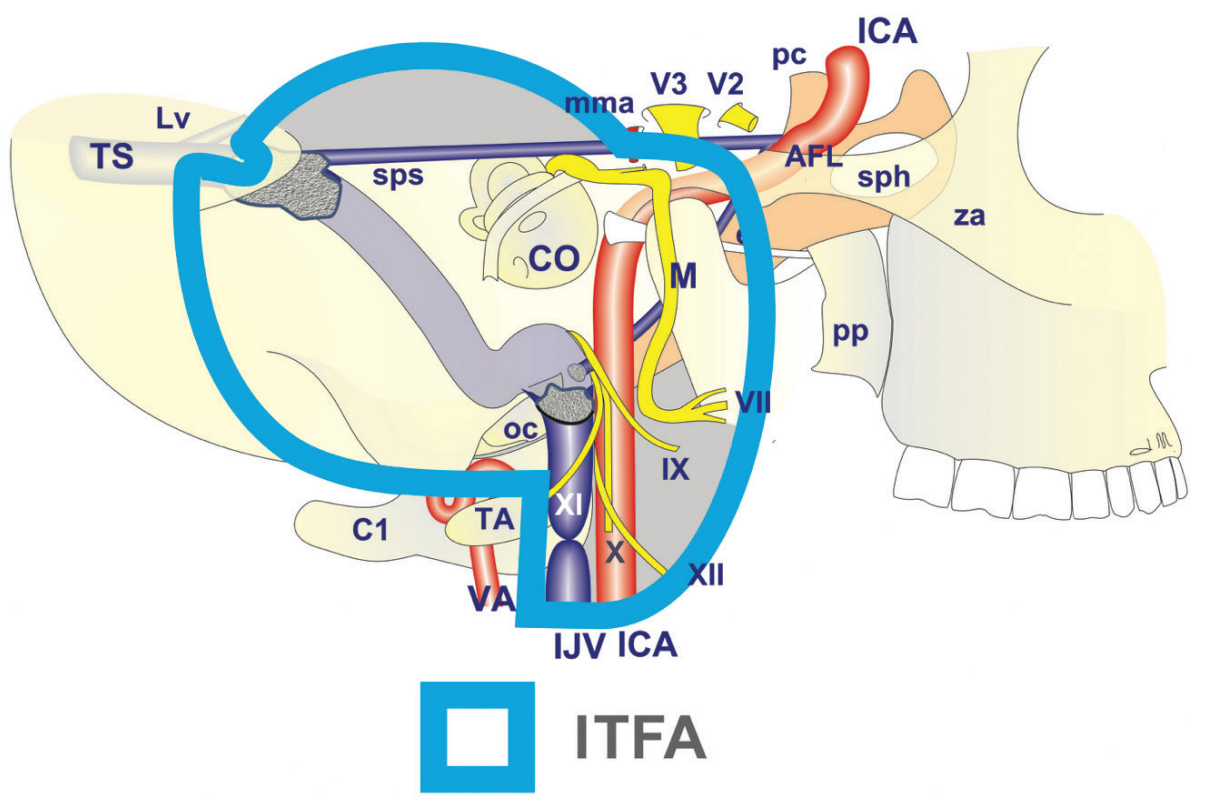

Figure 2 Transcondylar, transtubercular extension improves postero-inferolateral and medial exposure. 


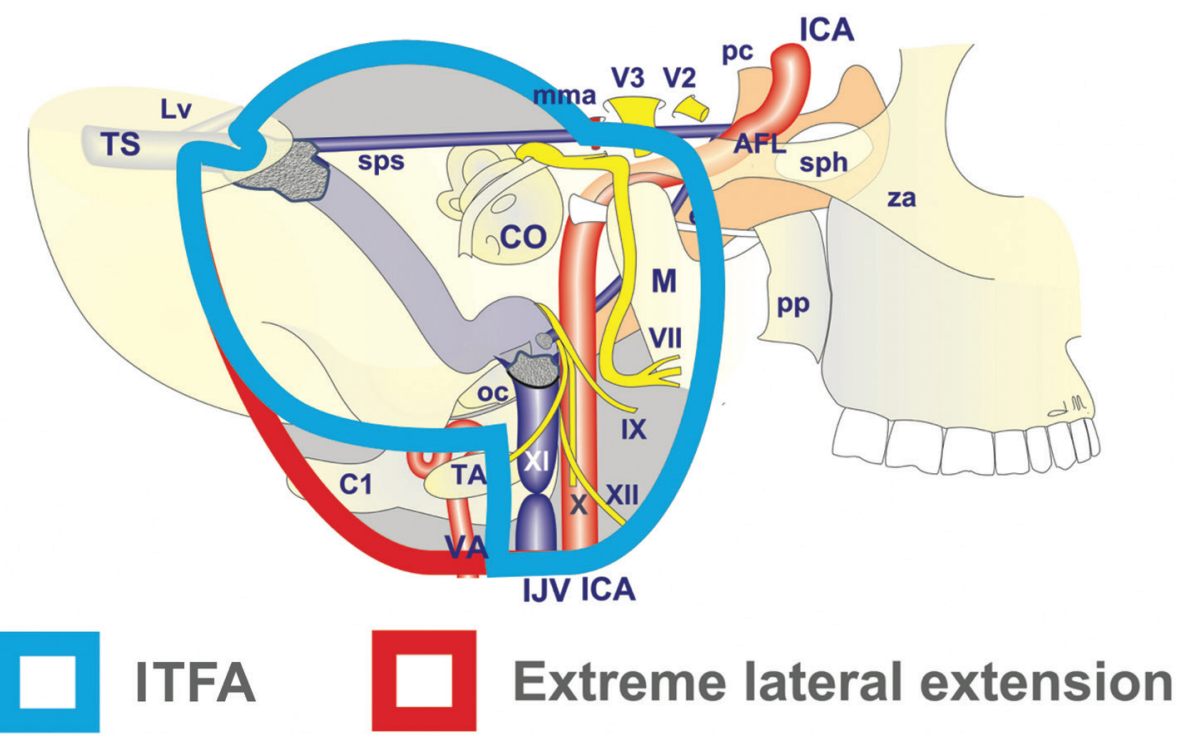

Figure 3 Far lateral approach further extends postero-inferolateral exposure.

\section{STEPS OF ITFA-A WITH TRANSTUBERCULAR- TRANSCONDYLAR EXTENSION}

As described in the previous sections, the ITFA-A is performed. The transcondylar-transtubercular approach begins with the identification of the splenius capitis muscles. The posterior fossa dura is uncovered toward the occipital skull base in order to start drilling of the jugular process and occipital condyle. The drilling of the jugular process is commenced followed by the identification and drilling of the occipital condyle superior to the atlanto-occipital joint posteromedial to the JB. The hypoglossal canal is then identified between the jugular tubercle and the occipital condyle above the vertebral artery, if indicated.

Tumor removal is commenced at this point. The IJV is closed with vascular clips. The IJV is mobilized up to the jugular fossa by mobilizing it away from the spinal accessory nerve. The tumor is peeled away from the dura of the posterior cranial fossa. The infiltrated bone of the fallopian canal and tympanic bone is then drilled out. The tumor is debulked from the JB area. The infiltrated infralabyrinthine cells are drilled out. The sigmoid sinus is opened to expose the tumor within. The IJV is opened to expose the distal end of the tumor. The inferior petrosal sinus is packed with Surgicel ${ }^{\circledR}$ packing. The tumor is then separated from the LCNs. The ICA is identified after extensive drilling of the bone of the vertical portion of the carotid canal and the tumor around is coagulated with bipolar coagulation. The tumor is gently separated from the wall of the ICA. Further drilling of all the suspect bone of the infralabyrinthine and apical cells is carried out until complete removal is accomplished. If required, the internal carotid artery is 
partially mobilized and the infiltrated clivus is drilled out. The posterior fossa dura is not opened and the intradural portion of the tumor is left behind, to be removed in a second stage. Closure of the Eustachian tube, cavity obliteration, and watertight closure of the subcutaneous and cutaneous tissues are carried out as with conventional ITFA-A.

\section{CONSIDERATIONS IN THE MANAGEMENT OF COMPLEX TJPS}

Complex TJPs, which include multiple tumors or tumors that have been previously dealt with by surgery or radiotherapy, pose unique challenges to even the most experienced skull base surgeon. The following issues need to be taken into consideration while managing such complex cases.

\section{Large tumors}

Large TJPs extend along the internal carotid artery and into the petrous apex or intradurally destroying the medial wall of the JB involving the LCNs along the way. C3 and C4 tumors are generally considered large tumors. C2 tumors can be managed using the ITFA-A, while $\mathrm{C} 3$ or $\mathrm{C} 4$ tumors can be dealt with using the ITFA-A alone or in combination with ITFA type B. If the tumor if found to involve the clivus, the occipital condyle, or the foramen magnum, the modified transcochlear approach can be used.

\section{Large intradural extension}

A large intradural extension can be managed either by a single-stage or by a twostage surgery (24). Our experience has shown that a planned second-stage resection may be preferable in case of extensive dural involvement. The advantage of two-stage surgery is that a clear plane of dissection can be established between the tumor and the brain stem due to the devascularization of the tumor after the firststage surgery and subsequent shrinkage of the intradural mass (Figure 4A-D). Another reason for staging the surgery is the argument that LCNs involved with tumor would need to be sacrificed, resulting in severe cough. This would lead to an increase in intracranial pressure facilitating cerebrospinal fluid leaks (40). We prefer to stage surgery when tumors have over $2 \mathrm{~cm}$ of intradural extension. For the second stage, a petro-occipital-trans-sigmoid (POTS) approach is preferred, but a modified transcochlear approach or an enlarged translabyrinthine approach may also be used.

\section{Extension to the foramen magnum, clivus, or cavernous sinus}

Tumors extending to the foramen magnum, clivus, or cavernous sinus are considered complex cases. These areas can be reached by a modified transcochlear approach or an enlarged translabyrinthine approach (37). Drilling of the clival bone until healthy bone is reached is important to ensure total disease clearance. 

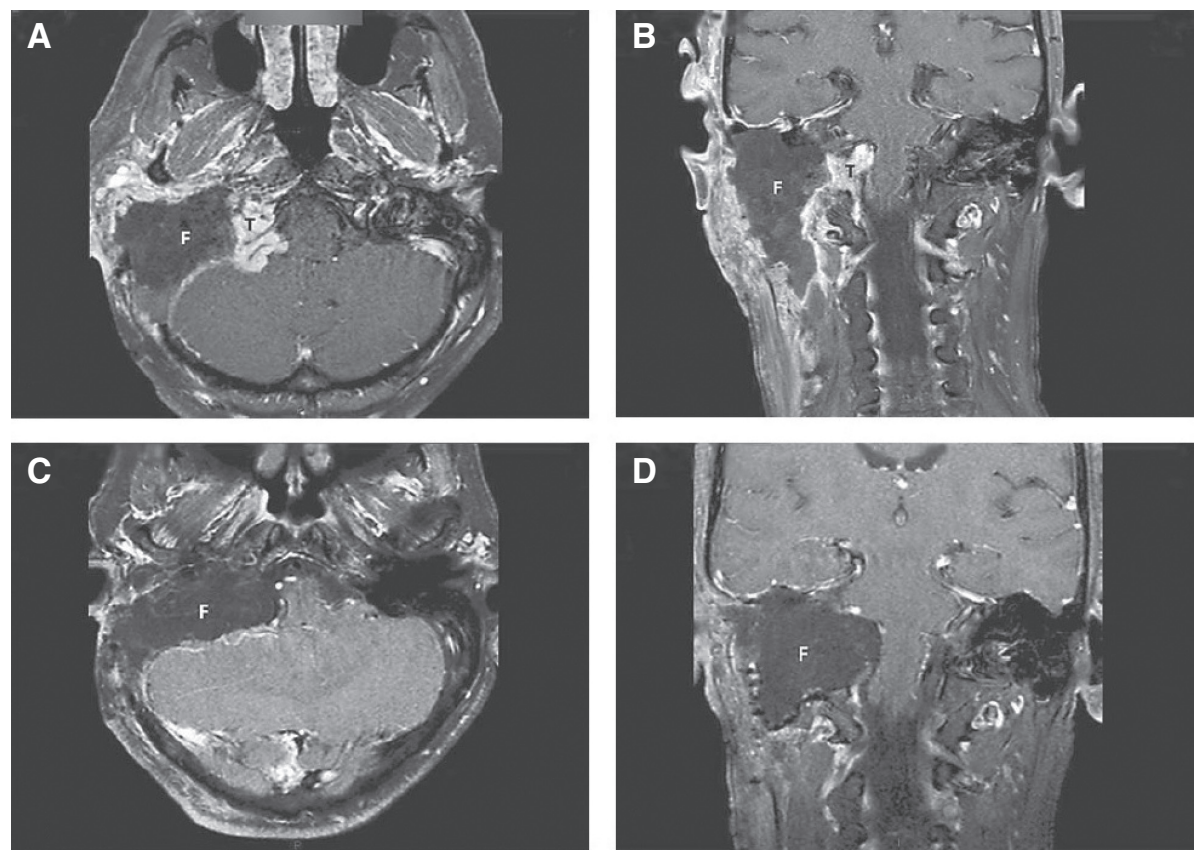

Figure 4 Imaging. (A and B) MRI, axial, and coronal views after the first-stage surgery. The residual intradural tumor is noted. The surgical defect is filled with abdominal fat. (C and D), $\mathrm{MRI}$, axial, and coronal views after the second-stage surgery. After the surgery, there is no residual tumor. F, fat; T, intradural tumor.

\section{Involvement of the ICA}

By classification, TJPs involve the ICA due to their close anatomical proximity (8). Dissection from the ICA can be achieved by subperiosteal dissection in the carotid canal or sub-adventitial dissection in the vertical portion (41). However, when the artery is stenosed or surrounded to a great extent by tumor ( $>270$ degrees), manipulation without endovascular intervention may be risky (42). Permanent balloon occlusion $(\mathrm{PBO})$ can be performed when the ICA is infiltrated by tumor, if there is evidence of adequate collateral blood flow. In case of insufficient collateral flow, it is suitable to perform an intraluminal stenting of the artery (Figures 5A-D and 6). We have introduced stenting of the cervical and petrous segments of ICA since early 2003 as a method to avoid pre-operative closure of the ICA or high-risk bypass procedures and to protect the artery during surgery (43-46). Stenting of the ICA reinforces the artery and allows more aggressive carotid dissection and mobilization of the artery when necessary (24)

\section{Single ICA on the lesion side}

In the case of a single carotid artery on the side of the lesion, the possible management options include "wait and scan," partial resection, followed by radiotherapy 

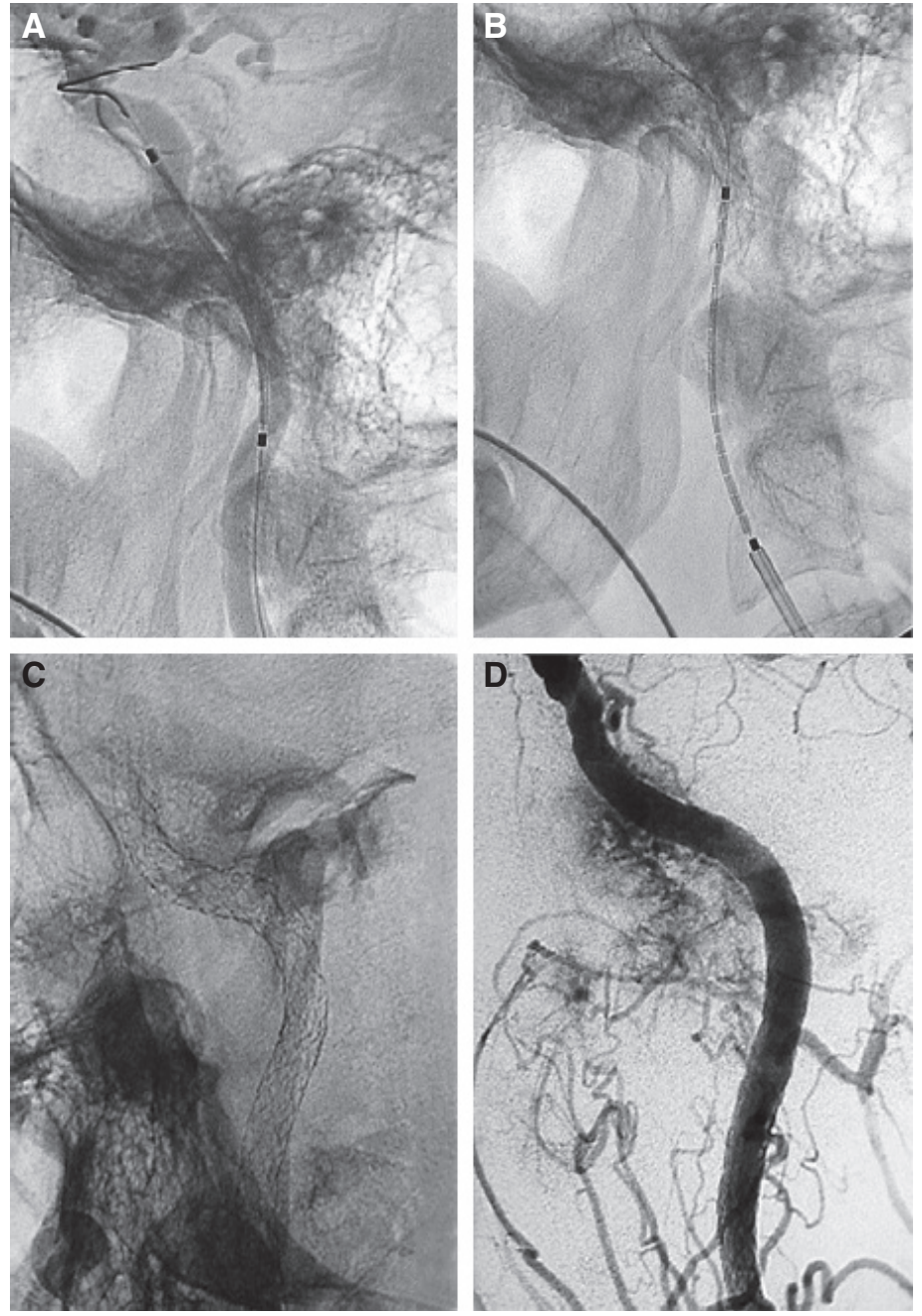

Figure 5 Stent insertion. (A and B) Insertion of the stents in the petrous and cervical portions of the internal carotid artery (ICA). (C) Digital x-ray in oblique projection showing the stents fully deployed into the petrous and cervical segments of the ICA. (D) Digital subtraction angiography of the ICA after stenting showing resolution of the stenosis.

or total removal after preoperative reinforcement with stents $(44,47)$. Bypass surgery in such patients can lead to cerebral ischemic damage; hence, stenting is considered the best option.

\section{Vertebral artery involvement}

TJPs involving the VA are extremely uncommon. Only 11 cases were reported worldwide, of which eight belong to our series. We emphasized the importance of 


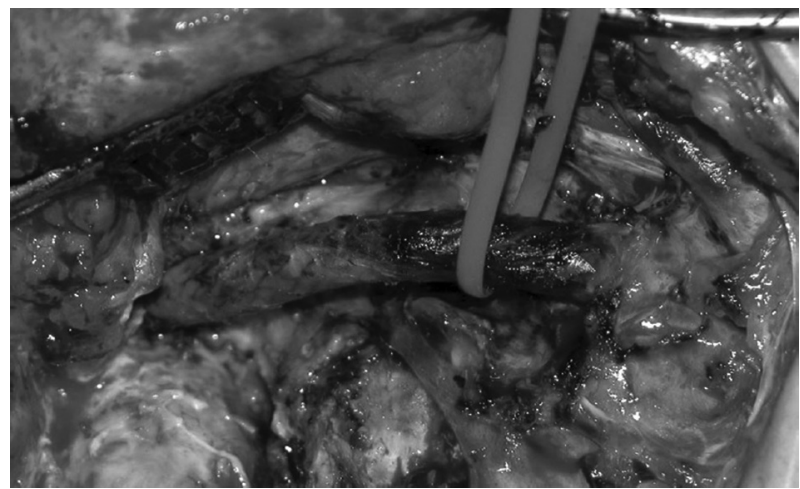

Figure 6 The view of the internal carotid artery. Tumor removal has been completed. Dissection has been carried out down to the stent in an almost bloodless field.

vertebral artery involvement in paragangliomas by introducing a "V" Class to the Fisch classification (2). Therefore, the vertebrobasilar system must always be included in the angiographic assessment of TJPs planned for surgery. Apart from the assessment of the VA directly, this is also useful for detecting anastomotic connections between the external carotid and the VA, which are potentially dangerous during embolization (48). The involvement of the V3 segment of the VA requires the employment of an extreme lateral extension to standard ITFA-A. As mentioned above, we prefer two-stage surgery in the case of large intradural extension (Figure 7A-F).

\section{Dominant or unilateral sigmoid sinus on the lesion side}

Obliteration of the sigmoid sinus and closure of the jugular vein are almost an integral step in surgery for TJPs. However, ligation of the sigmoid sinus cannot be performed when it is the dominant or only sigmoid sinus. In fact, ligation may lead to intracranial hypertension, venous congestion, and brain edema (37). Under such circumstances, the ipsilateral mastoid emissary vein or the condylar vein has to be preserved whenever possible. When the collateral venous drainage cannot be preserved, a more conservative treatment plan, such as partial resection with preservation of the SS, gamma knife surgery, or a "wait and scan" approach, is recommended.

\section{Bilateral or multiple HNPs}

In the management of bilateral TJPs, the possibility of bilateral deficits of important LCNs looms large and hence neural preservation is very important to achieve a good quality of life for the patient post-operatively. According to our management protocol, in patients presenting with LCN deficits on the side of the larger tumor, surgery is recommended on that side first, following which the smaller tumor is either followed up or irradiated. On the contrary, if the patients present with LCN deficits on the side of the smaller tumor, surgery is performed on the smaller tumor, following which the larger tumor is followed up with MRI. 

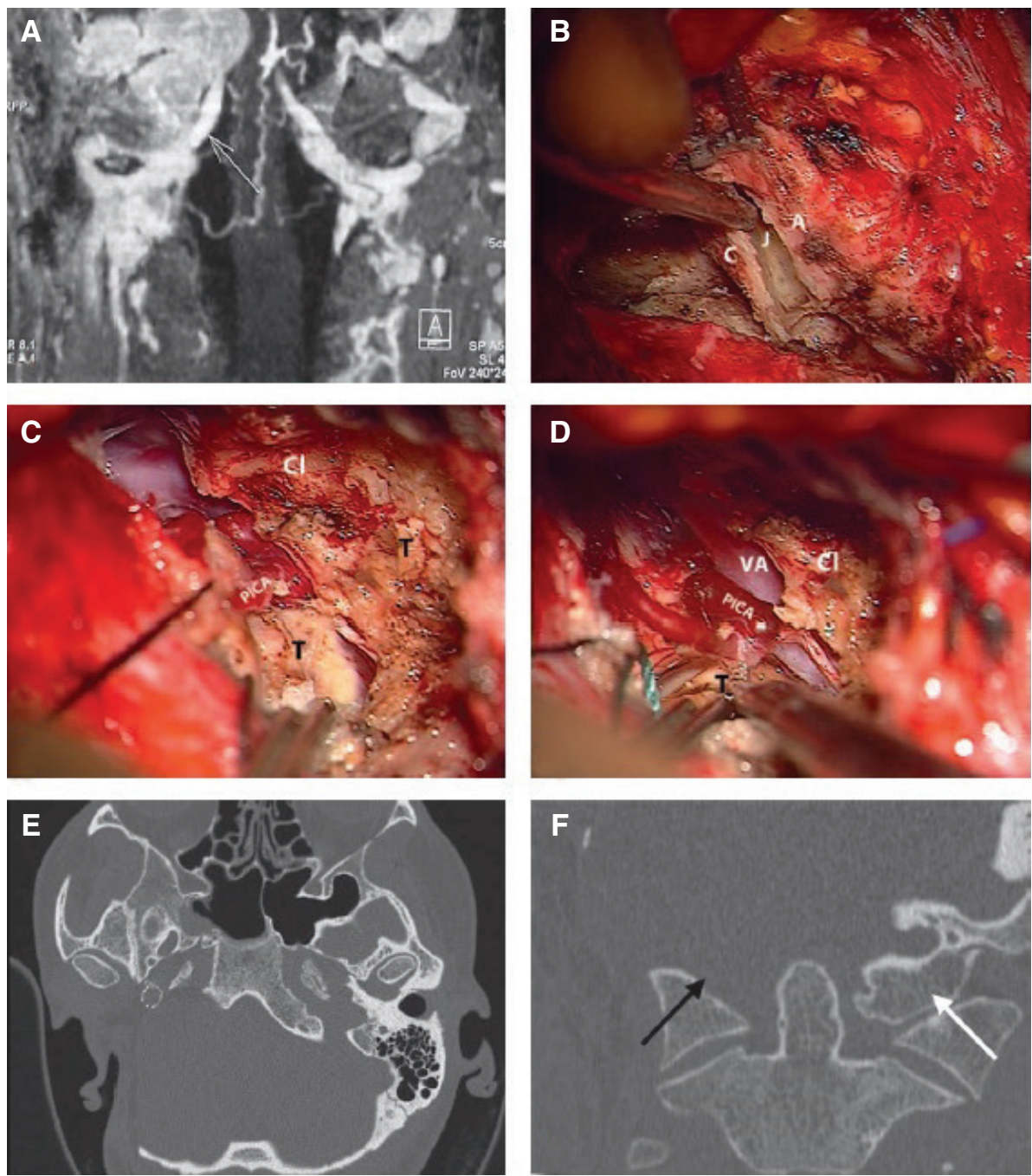

Figure 7 (A) A class C4Di2Vi tumor. MRI coronal image showing the tumor attached to the VA. (B-F) Surgical sequences of extreme lateral transcondylar approach. (B) The transverse process of the atlas $(\mathrm{A})$ is drilled out and the atlanto-occipital joint $(\mathrm{J})$ is removed. $\mathrm{C}=$ Condyle. $(\mathrm{C})$ The tumor $(\mathrm{T})$ is attached to the vertebral and posteroinferior cerebellar arteries infiltrating the clival $(\mathrm{Cl})$ bone, which is partially drilled out. (D) The tumor is separated from the PICA. (E) CT scan. Axial view showing the stent in the ICA and the extent of bone removal. (F) CT scan coronal view showing the absence of the surgically removed occipital condyle (black arrow) compared to non-operated side (white arrow).

During follow-up, if the larger tumor shows evidence of growth, a subtotal resection may be performed with the preservation of LCN function or the patient may be irradiated. In patients with no presenting LCN deficit, a "wait and scan" approach is first applied. However, if the tumor shows growth, radiotherapy or subtotal removal of the tumor with LCN preservation is performed first. 
Subsequently, if the tumor continues to grow despite radiotherapy or surgical removal, the other remaining treatment modalities can be applied.

\section{Recurrence after previous surgery, radiotherapy, or stereotactic radiosurgery}

Any revision surgery is a challenge, as there are no normal tissue planes and surgical landmarks. Previous surgery or radiation increases the risk of cerebrospinal fluid leak and the risk of damage to the LCNs and FN $(37,42)$. The carotid canal is the most common site for recurrence in TJPs, and previous dissection increases the risk of injury to the ICA. In such cases, the preoperative management of the ICA by PBO or stenting is especially important. An ITFA-A with FN rerouting is recommended in all cases.

\section{GENETICS OF TJP}

Paragangliomas have a strong genetic basis, being frequently ( $\approx 40 \%$ of the cases) associated with predisposing germline mutations in one of at least 15 nuclear genes, most relevantly $S D H A / B / C / D$, that encode the four subunits of succinate dehydrogenase (SDH), a nuclear-encoded mitochondrial enzyme participating in both oxidative phosphorylation and the Krebs cycle, and SDHAF2, whose product is required for SDHA protein flavination (collectively the SDHx genes) (49). Head and neck paragangliomas are most frequently associated with mutations in SDHC and SDHD and, to a lesser extent, $\operatorname{SDHB}(50,51)$. Patients with multifocal tumors often carry SDHD mutations, but in any case the metastatic potential is low $(50,51)$. Few genetic data are available for TJPs. The 41 TJP cases reported in our recent study (52) were analyzed for SDHA/B/C/D/AF2 mutations at the Veneto Institute of Oncology, Padua, Italy. The median age at surgery for this series was 47 years (15-76 years): 21 patients were males and 20 were females. Overall, germline SDHx mutations were detected in 15/41 cases (36.6\%). A germline SDHx mutation was found in 14 cases, respectively, mutated in SDHA, 1 case; SDHB, 5 cases; SDHC, 6 cases; SDHD, 2 cases; SDHAF2, 1 case. Thus, the SDHx mutation frequency in our TJP subset is comparable to that of paragangliomas in general and suggests a preference for mutations in SDHC and SDHB. This may be relevant, given that $S D H B$ mutation carriers are at higher risk of malignant paraganglioma.

\section{DEVELOPMENTAL ORIGIN}

As indicated by ultrastructural analysis, paragangliomas incorporate dysmorphic variants of the vascular (i.e., endothelial), perivascular (i.e., pericytic), glial (i.e., sustentacular), and neuroepithelial (i.e., chief) cells found in normal paraganglia (Figure 8) and may therefore provide a classic example of multipotent organoid tumorigenesis (52). In fact, our recent data, based on unique patientderived in vitro and in vivo models, indicate that head and neck paragangliomas 


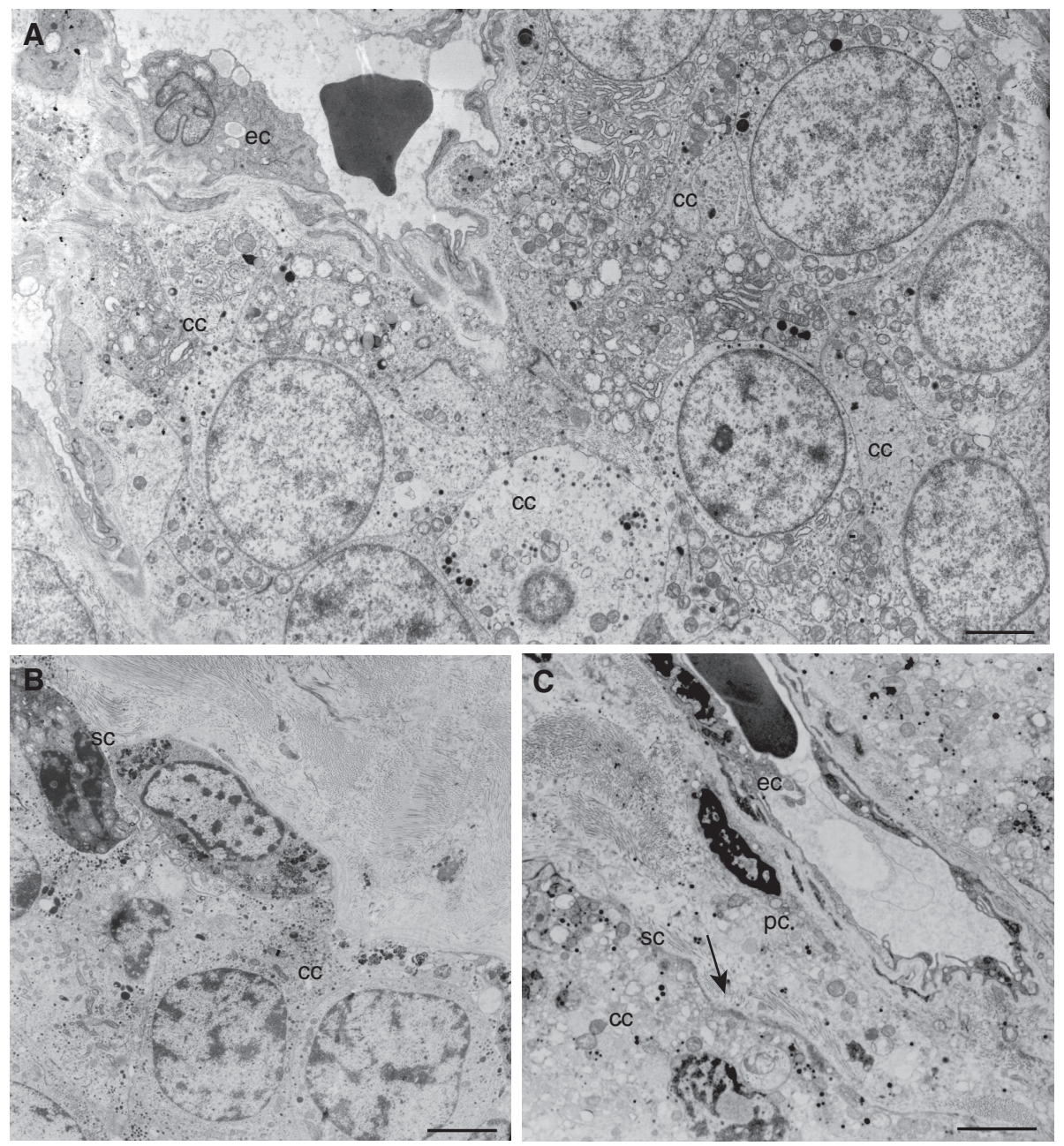

Figure 8 Ultrastructural relationships among the main paraganglioma cell types, as exemplified in jugulotympanic tumors. (A) Chief cells (CC), characterized by ovoid nuclei with focally condensed heterochromatin clumps and "salt and pepper" nucleoplasm, abundant cytoplasm with vacuolizations and swollen mitochondria, are situated close to a capillary lined by atypical endothelial cells (ec). (B) Sustentacular cells (sc), characterized by elongated nuclei and thin cytoplasm with abundant lipofuscin granules, indicative of oxidative stress, lie at the periphery of a nest of cc. (C) Ultrastructural relationships between the major paraganglioma cell types, which include cc, sc (only thin cytoplasmic projections along a cc are visible here), perycytes (pc), and ec. Bars: A, $10 \mu \mathrm{m}$; B-C, $6 \mu \mathrm{m}$.

are sustained by tumorigenic stem-like cells that engage in dysregulated histo/ organogenetic processes $(52,53)$. We found that head and neck paragangliomas, including TJPs, contain stem-like cells with hybrid mesenchymal/vasculoneural phenotype that are stabilized and expanded in culture. The paraganglioma cultures depended on the downregulation of the miR-200 and miR-34 families, which we found responsible for the control of NOTCH1, PDGFRA, and ZEB1 
protein expression levels $(52,53)$. High levels of these proteins, which are implicated in the promotion of the epithelial to mesenchymal transition, appear to sustain paraganglioma tumorigenesis. Both paraganglioma- and cell culturederived xenografts recapitulated the typical vasculoneural paraganglioma structure. In our models, the histogenesis of the tumor tissue followed a hierarchy that originated from primitive mesenchymal-like neoplastic cells (52). Vasculoangiogenesis appeared to be the earliest developmental phase, and neurogenesis depended on the creation of a perivascular niche. Neuroepithelial differentiation was associated with severe mitochondrial dysfunction, not present in cultured paraganglioma cells, but acquired in vivo during xenograft formation. Importantly, it may provide a therapeutic target, possibly exploitable in the clinical setting to prevent tumor recurrence after surgery. In fact, imatinib, which interferes with endothelial-mural signaling, blocked paraganglioma xenograft formation. These results were unaffected by the SDHx gene carrier status of the patient, pointing to a common mechanism of tumor origin, regardless of the heterogeneity of the paraganglioma predisposing genes (52). Importantly, ZEB1 expression and the epithelial to mesenchymal transition, which appear to support paraganglioma development, are known to confer resistance to chemotherapy and radiotherapy, which may agree with scattered clinical evidence indicating that paragangliomas resist to these therapeutic approaches (52).

\section{HISTOPATHOLOGY}

The data presented here are based on the literature and on the personal experience, derived from the diagnostic analysis of 94 TJP cases who underwent surgery at the Otology and Skull Base Unit, Gruppo Otologico, Piacenza, from 2002 to 2016. TJPs are usually smaller than carotid and vagal paragangliomas, and TJPs of the cassa tympani are in turn smaller $(<1 \mathrm{~cm})$ than those growing in the foramen jugular, at the cranial base or in the petrous bone. However, it must be said that only few TJP cases come to pathologists as sizeable tumor masses. In fact, the use of preoperative embolization and electrosurgery to reduce intraoperative bleeding and the piecemeal excision strategy necessary to remove tumor tissue growing within hard bone and along vessels and nerves make fragmentation and surgical artifacts unavoidable. The size of these fragments typically varies from a few millimeters to over $2 \mathrm{~cm}$, exceptionally up to $5 \mathrm{~cm}$ in the major axis. The consistency is typically rubbery, but bone particles may be present and, if so, decalcification treatment may be mandatory. The very fact that most pathology specimens consist of irregular and partially necrotic fragments, crushed and altered by thermal injury, makes intraoperative diagnosis challenging, which explains why it is generally not requested. On the other hand, the pathologist is often asked only to confirm a diagnosis already proposed with a high degree of probability by the surgeon. Intraoperative diagnostic questions which impact on the surgical strategy arise only rarely, and mostly in cases with peculiar presentation (e.g., abnormal extension into the petrous part of the temporal bone, into and/or along the dura mater, or in the middle and external ear).

As other paragangliomas, TJPs generally show a well-defined organoid structure (54). The distinctive morphological units are classically defined as "zellballens," due 
to their appearance in histological sections, where they present as nests or ribbons of relatively homogeneous, tightly compacted nests of epithelioid cells (chief cells) separated by a lace of vessels and/or fibrous tissue (Figure 9A). As highlighted using transmission electron microscopy (Figure 8), the zellballens are peripherally delimited by a thin rim of elongated glia-like nurse (sustentacular) cells, not easily recognizable by morphology but readily identifiable with an IHC reaction for S100 (Figure 9B-C). These cells surround the zellballens with their thin cytoplasmic extensions that may also insinuate within, sustaining and supporting the chief cells (53). Some peculiar features appear to be more frequent in TJPs than in other paragangliomas. These include the following: (i) the zellballens tend to be less uniform in size and are frequently smaller, (ii) the chief cells tend to be smaller (55), (iii) there is frequent evidence of bone infiltration, and (iv) the tumor tissue tends to be more vascular (54).

With regard to 3D structure, it is evident that the zellballens are not isolated, but form a continuous reticulum where single tracts are of variable thicknesses. This can be easily appreciated with immunostaining reactions for chief cells (e.g., chromogranin A, synaptophysin), for sustentacular cells (e.g., S100), and for endothelial cells (e.g., CD34).

Fibrosis or sclerosis, a common feature in TJPs (54), usually occupies 5-25\% of the tumor section area, although it may occasionally extend up to $80 \%$ and may distort the zellballens, simulating invasive carcinoma (53). Thus far, a sclerosing paraganglioma variant has been described mainly in mediastinal locations (57). Some TJPs mimic vascular lesions (hemangioma or hemangiopericytoma) (56) in that they present ectatic vessels, apparently devoid of blood due to surgical manipulations but prominent relative to the zellballens (54).

We never observed in our TJP series the peculiar small cell variant with "neuroblast-like" cells and fibrillar matrix, interpreted as a composite neoplasm, that is, paraganglioma with a neuroblastic component (54). Using light microscopy, we also never found evidence of the pigmented variety, characterized by lipofuscin or melanin accumulation. This variant was reported in various paraganglioma locations, including the vagal one, but not in the tympano-jugular area (58). However, using electron microscopy, we always detected in our TJP series evidence of lipofuscin generation in the form of oxidized lipid droplets, particularly in sustentacular cells (Figure 8).

As mentioned above, histological evidence of bone infiltration is nearly constant ( $70 \%$ of the cases in our series) and may not point to particularly aggressive tumor potential. On the other hand, massive necrosis and hemorrhage are rare ( $4 \%$ in our series) and may correlate with infiltration of large vessels and/or preoperative embolization. In fact, common iatrogenic features include focal or extensive necrosis, granulomatous reactions, and/or crushing and burning artifacts, which, when massive, make morphological diagnosis difficult or impossible.

Chief cells are homogeneous, round or oval, with a round nucleus, inconspicuous nucleolus, and granular cytoplasm, variably staining from amphophilic to pink. On histological sections, their diameter varies from 7 to $30 \mu \mathrm{m}$, being most frequently in the $12-15 \mu \mathrm{m}$ range. Sometimes, probably due to iatrogenic artifacts, the chief cells appear even smaller, with dark nucleus and poorly evident, shrunken cytoplasm on an empty background. Chief cells may also exhibit extensive cytoplasmic vacuolization (clear cell change) (56). Very large isolated 

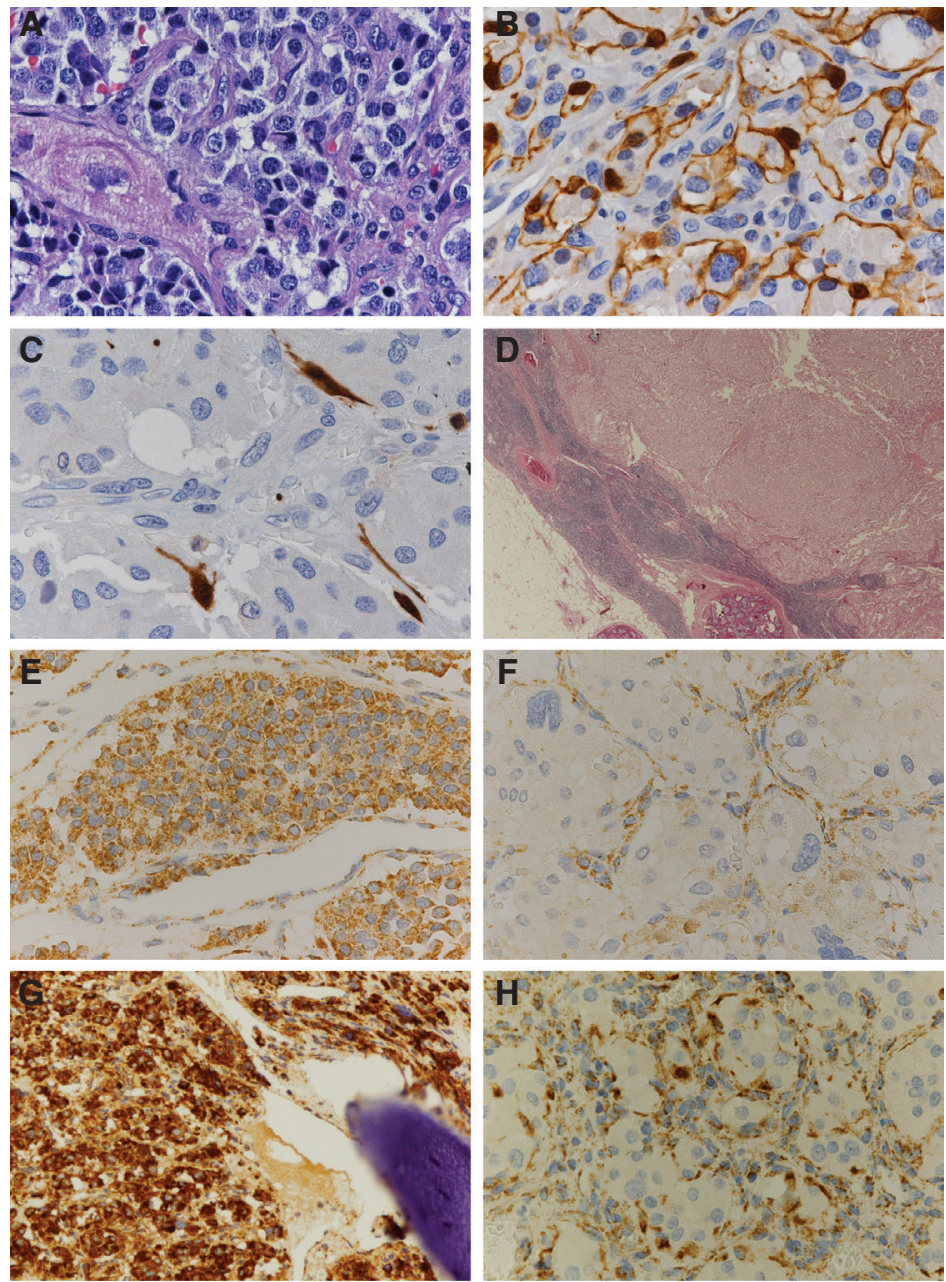

Figure 9 Typical histopathological and immunohistochemical features in jugulotympanic

paragangliomas. (A) Classic morphology, characterized by tightly packaged nests ("zellballens") of rather uniform chief (neurosecretory) cells. (B) Variant morphology in another jugulotympanic paraganglioma, where "zellballens" of small diameter are highlighted by the dark brown immunohistochemical stain for the S100 protein, a marker of the sustentacular cells, which encircle the chief cells. Notably, the sustentacular cells display both nuclear and cytoplasmic S100 positivity. (C) Distinct morphological variant, where the sustentacular cells, highlighted by dark brown S100 immunostaining, are less abundant, while the zellballens are better organized and composed of larger chief cells. (D) Massive lymph node metastasis from a jugulotympanic paraganglioma showing focal iatrogenic embolization. (E) Intense SDHB positivity in all the cellular components (chief, sustentacular, and vascular cells) of a jugulotympanic paraganglioma not mutated in the $S D H x$ genes. (F) Selective loss of SDHB immunostaining in chief cells and SDHB positivity of the other cell types (vascular and sustentacular) in a case mutated in SDHB. (G) Strong SDHA immunopositivity in all cell types, including chief cells, in a case infiltrating the temporal bone. This case did not carry mutations in SDHA. (H) Selective loss of SDHA immunostaining in chief cells and SDHA positivity of the other cell types in a case carrying an SDHA mutation. (A, D: H \& E) Original magnifications 400x (A) and 20x (D); (B, C, E, F, G, H, G) Avidin-biotin complex immunoperoxidase, counterstained with $\mathrm{H} \& \mathrm{E}$, original magnifications 400x (B, C, E, F, H) and 200x (G). 
cells ("atypical cells") with vesicular, hyperchromatic, or even vacuolated nuclei are seen in a significant fraction of cases (18\% in our experience) and their relevance is debated, although they are clearly not reliable as indicators of potential malignant behavior $(54,56,59,60)$. Mitoses are generally rare $(<1$ in 10 highpower microscopic fields) (56) and in our experience are practically absent.

Chief cells constantly show strong and diffuse immunoreactivity for synaptophysin, even in the presence of extensive artifacts. Chromogranin and vimentin staining are also characteristic, even if variable in different fields, which is also the case for other neuroendocrine markers, such as CD56 and NSE. The occurrence of paragangliomas negative for both chromogranin A and B has been reported (59). In a few cases, chief cells are stained with S100, as sustentacular cells. As other paragangliomas, TJPs are always negative for cytokeratins (60).

In our experience, the number of sustentacular cells is highly variable (from 0 to 60/HPF) (Figure 9B-C), with an average of 25 cells/HPF. Cases with abundant sustentacular cells tend to show very small zellballen diameters, down to microsheets of a single chief cell encircled by a single sustentacular cell. These patterns are difficult to interpret in terms of clinical significance. In fact, in a single case of lymph node metastasis, we found that the number of sustentacular cells ranged from 0 to 21 per high magnification field (400x).

The proliferative index, as determined with Ki67 immunostaining, is usually low, varying from 1 to $2 \%$; only rare cases have higher proliferative indexes, ranging from 3 to $7 \%$.

According to the literature $(56,59,61,62)$, there are no established clinical, histological, or immunohistochemical criteria that predict the biological behavior of TJPs. In fact, nuclear pleomorphism, mitotic activity, necrosis, or vascular or perineural invasion can be found in the so-called "benign" forms, as in the rare cases that metastasize to distant sites (60). Even immunohistochemistry for the proliferation marker Ki67, useful and applied in many neoplasms, is of no help, as it can result very low even in metastatic cases and there is no standardized cutoff value for its interpretation. Therefore, malignancy can be established only by the occurrence of lymph node and/or distant metastases (Figure 9D). The overall reported frequency of metastases in head and neck paragangliomas is less than 5\% (59), but in TJPs it seems to be lower, possibly 2-4\% (63). In a review of 53 metastatic cases, metastases involved, in order of frequency, bone, lungs, lymph nodes, liver, and other locations, and they presented up to 30 years after initial treatment (64)

However, recent studies have clearly indicated that head and neck paragangliomas that harbor SDHB gene mutations are more prone to develop metastases (61). Thus, immunostaining for the SDHB protein has become a fundamental screening tool. The high sensitivity (84-100\%) and specificity (74-85\%) of SDHB immunohistochemistry has been confirmed in various important studies (65-67). In cases not mutated for any of the SDH genes, the immune reaction for the SDHB protein stains with high intensity all the paraganglioma tissue components, including chief, sustentacular, and vascular cells (Figure 9E), while SDHB immunostaining results negative in the chief cells of the cases harboring mutations not only in SDHB but, with less consistency, also in SDHA, SDHAF2, SDHC, and SDHD (65) (Figure 9F). Similarly, in non SDHA mutated cases, SDHA immunostaining marks all cell types, including chief cells (Figure 9G), while the rare cases harboring an 
SDHA mutation show loss of SDHA immunostaining in chief cells (Figure 9H) (59). In the subset of our TJP series thus far analyzed for SDHB immunohistochemistry, we found SDH gene family mutations, concordant with SDHB loss, in nearly $40 \%$ of the cases (27/69) and of SDHA mutations in only $2.8 \%(2 / 69)$ of cases. So far, only 1 of the 27 cases positive for SDHB mutation has metastasized.

Histopathologically, the differential diagnosis of TJP includes the tumors more frequently encountered in the specific TJP location: in the jugular and intracranial region meningioma (68), schwannoma (23), and even the rare meningeal hemangiopericytoma; in the acoustic channel middle ear adenoma (54), which often shows endocrine differentiation. Unusual neoplasms that should also be considered include endolymphatic sac tumor and metastatic lesions, particularly from renal cell carcinoma (54), melanoma, and salivary gland carcinomas. Finally, given that paragangliomas can occur even in intra/parasellar locations (69), hypophyseal adenoma might have to be considered in differential diagnosis. Apart from morphology, combined immunohistochemistry for synaptophysin, S-100 and cytokeratin usually resolves diagnostic doubts.

\section{CONCLUSION}

Paragangliomas are sluggish, generally slow-growing tumors that rarely metastasize and are thus considered of benign nature. However, they steadily grow along the regional neurovascular bundles, are highly infiltrating, and appear to be resistant to radiotherapy/chemotherapy (52). Therefore, surgery remains the mainstay of treatment. This is particularly challenging for TJPs, which arise at the skull base and necessitate particular surgical skills, available only at few highly specialized centers. We covered in this chapter the technical developments and the novel approaches that, in the last two decades, made curative surgery of TJPs possible. Nonetheless, there is a need to develop new paradigms of treatment for inoperable, recurring, or metastatic TJPs. This requires a thorough understanding of the etiology of paraganglioma, where factors, both genetic and environmental, that impact mitochondrial metabolism and cellular differentiation appear to be implicated (52). Importantly, preclinical evidence suggests that treatments that interfere with vasculogenesis may prevent paraganglioma formation in a murine xenograft model (52). This might open the way for the development of postsurgical therapies aiming at the prevention of disease recurrence (52). Further research is needed to build up knowledge and tools that could allow further and hopefully decisive improvements in the prevention and therapy of TJPs and of paragangliomas in general.

Acknowledgments: This work was supported by the Italian Association for Cancer Research (AIRC) through grants IG9168 (2009-2012) and IG16932 (2015-2017) to RMC. We gratefully acknowledge the services provided by the Mario Sanna Foundation Onlus, Piacenza, Italy, dedicated to the prevention and treatment of skull base tumors. We thank Ms Anna Nassani, Department of Anatomic Pathology, Guglielmo da Saliceto Hospital, for her kind and expert help with immunohistochemistry. 
Conflict of interest: The authors declare no conflicts of interest with respect to research, authorship, and/or publication of this book chapter.

Copyright and permission statement: We confirm that the materials included in this chapter do not violate copyright laws. Where relevant, appropriate permissions have been obtained from the original copyright holder(s). All original sources have been appropriately acknowledged and/or referenced.

\section{REFERENCES}

1. Arriaga MA, Day DJ. Neurosurgical issues in otolaryngology. Philadelphia, PA: LWW; 1999.

2. Shin SH, Sivalingam S, De Donato G, Falcioni M, Piazza P, Sanna M. Vertebral artery involvement by tympanojugular paragangliomas: Management and outcomes with a proposed addition to the Fisch classification. Audiol Neurootol. 2012;17(2):92-104. http://dx.doi.org/10.1159/000330724

3. Moe KS, Li D, Linder TE, Schmid S, Fisch U. An update on the surgical treatment of temporal bone paraganglioma. Skull Base Surg. 1999;9(3):185-94. http://dx.doi.org/10.1055/s-2008-1058145

4. Sanna M, Shin SH, Piazza P, Pasanisi E, Vitullo F, Di Lella F, et al. Infratemporal fossa approach type a with transcondylar-transtubercular extension for Fisch type C2 to C4 tympanojugular paragangliomas. Head Neck. 2013;36(11):1581-8. http://dx.doi.org/10.1002/hed.23480

5. Sanna M, Flanagan S. The combined transmastoid retro- and infralabyrinthinetransjugular transcondylar transtubercular high cervical approach for resection of glomus jugulare tumors. Neurosurgery. 2007;61(6):E1340; author reply E1340. https://doi.org/10.1227/01.neu.0000306136.66849.5c

6. Jackson CG. Glomus tympanicum and glomus jugulare tumors. Otolaryngol Clin North Am. 2001;34(5):941-70, vii. http://dx.doi.org/10.1016/S0030-6665(05)70356-X

7. Jackler R, Brackmann D. Neurotology. St Louis, MO: Mosby; 1994.

8. Sanna M, Jain Y, De Donato G, Rohit, Lauda L, Taibah A: Management of jugular paragangliomas: The Gruppo Otologico experience. Otol Neurotol. 2004;25(5):797-804. http://dx.doi. org/10.1097/00129492-200409000-00025

9. Miman MC, Aktas D, Oncel S, Ozturan O, Kalcioglu MT. Glomus jugulare. Otolaryngol Head Neck Surg. 2002;127(6):585-6. http://dx.doi.org/10.1067/mhn.2003.130100

10. Foote RL, Pollock BE, Gorman DA, Schomberg PJ, Stafford SL, Link MJ, et al. Glomus jugulare tumor: Tumor control and complications after stereotactic radiosurgery. Head Neck. 2002;24(4):332-8; discussion 338-9. http://dx.doi.org/10.1002/hed.10005

11. Robertson JH, Gardner G, Cocke EW Jr. Glomus jugulare tumors. Clin Neurosurg. 1994;41:39-61.

12. Brown JS. Glomus jugulare tumors revisited: A ten-year statistical follow-up of 231 cases. Laryngoscope. 1985;95(3):284-88. http://dx.doi.org/10.1288/00005537-198503000-00008

13. Jackson CG, Kaylie DM, Coppit G, Gardner EK. Glomus jugulare tumors with intracranial extension. Neurosurg Focus. 2004;17(2):E7. http://dx.doi.org/10.3171/foc.2004.17.2.7

14. Michael LM 2nd, Robertson JH. Glomus jugulare tumors: Historical overview of the management of this disease. Neurosurg Focus. 2004;17(2):El. http://dx.doi.org/10.3171/foc.2004.17.2.1

15. Rosenwasser H. Glomus jugulare tumours. Proc R Soc Med. 1974;67(4):259-64.

16. Watkins LD, Mendoza N, Cheesman AD, Symon L. Glomus jugulare tumours: A review of 61 cases. Acta Neurochir. 1994;130(1-4):66-70. http://dx.doi.org/10.1007/BF01405504

17. Somasundar P, Krouse R, Hostetter R, Vaughan R, Covey T. Paragangliomas-A decade of clinical experience. J Surg Oncol. 2000;74(4):286-90. http://dx.doi.org/10.1002/1096-9098 (200008)74:4\%3C286::AID-JSO9\%3E3.0.CO;2-C

18. Pellitteri PK, Rinaldo A, Myssiorek D, Gary Jackson C, Bradley PJ, Devaney KO, et al. Paragangliomas of the head and neck. Oral Oncol. 2004;40(6):563-75. http://dx.doi.org/10.1016/j. oraloncology.2003.09.004

19. Young WF Jr. Paragangliomas: Clinical overview. Ann N Y Acad Sci. 2006;1073:21-9. http://dx.doi. org/10.1196/annals.1353.002 
20. Kaylie DM, O’Malley M, Aulino JM, Jackson CG. Neurotologic surgery for glomus tumors. Otolaryngol Clin North Am. 2007;40(3):625-49, x. http://dx.doi.org/10.1016/j.otc.2007.03.009

21. Jackler R, Brackmann D. Neurotology. 2nd ed. Philadelphia, PA: Elselvier Mosby; 2005.

22. Fisch U, Mattox DE. Microsurgery of the skull base. Stuttgart: Georg Thieme Verlag; 1988.

23. Ramina R, Maniglia JJ, Fernandes YB, Paschoal JR, Pfeilsticker LN, Neto MC, et al. Jugular foramen tumors: Diagnosis and treatment. Neurosurg Focus. 2004;17(2):E5. http://dx.doi.org/10.3171/foc.2004.17.2.5

24. Al-Mefty O, Teixeira A. Complex tumors of the glomus jugulare: Criteria, treatment, and outcome. J Neurosurg. 2002;97(6):1356-66. http://dx.doi.org/10.3171/jns.2002.97.6.1356

25. Pareschi R, Righini S, Destito D, Raucci AF, Colombo S. Surgery of glomus jugulare tumors. Skull Base. 2003;13(3):149-57. http://dx.doi.org/10.1055/s-2003-43325

26. Prasad SC, Mimoune HA, Khardaly M, Piazza P, Russo A, Sanna M. Strategies and long-term outcomes in the surgical management of tympanojugular paragangliomas. Head Neck. 2016;38(6):871-85. http://dx.doi.org/10.1002/hed.24177

27. Leonetti JP, Anderson DE, Marzo SJ, Origitano TC, Vandevender D, Quinonez R. Facial paralysis associated with glomus jugulare tumors. Otol Neurotol. 2007;28(1):104-6. http://dx.doi.org/10.1097/01. mao.0000244357.72626.f5

28. Lustig LR, Jackler RK. The variable relationship between the lower cranial nerves and jugular foramen tumors: Implications for neural preservation. Am J Otol. 1996;17(4):658-668.

29. Jackson CG, McGrew BM, Forest JA, Netterville JL, Hampf CF, Glasscock ME 3rd. Lateral skull base surgery for glomus tumors: Long-term control. Otol Neurotol. 2001;22(3):377-382. http://dx.doi. org/10.1097/00129492-200105000-00018

30. Rosenthal LH, Benninger MS, Deeb RH. Vocal fold immobility: A longitudinal analysis of etiology over 20 years. Laryngoscope. 2007;117(10):1864-70. http://dx.doi.org/10.1097/MLG.0b013e3180de4d49

31. Macdonald AJ, Salzman KL, Harnsberger HR, Gilbert E, Shelton C. Primary jugular foramen meningioma: Imaging appearance and differentiating features. AJR. 2004;82(2):373-7. http://dx.doi. org/10.2214/ajr.182.2.1820373

32. Suarez C, Sevilla MA, Llorente JL. Temporal paragangliomas. Eur Arch Otorhinolaryngol. 2007;264(7):719-31. http://dx.doi.org/10.1007/s00405-007-0267-3

33. Sanna M, Khrais T, Mancini F, Russo A, Taibah A. The facial nerve in temporal bone and lateral skull base microsurgery. Verlag: GeorThieme; 2006.

34. Som P, Curtin H. Head and neck imaging. 4th ed. St. Louis, MO: Mosby; 2003.

35. Mafee MF, Raofi B, Kumar A, Muscato C. Glomus faciale, glomus jugulare, glomus tympanicum, glomus vagale, carotid body tumors, and simulating lesions. Role of MR imaging. Radiol Clin North Am. 2000;38(5):1059-76. http://dx.doi.org/10.1016/S0033-8389(05)70221-9

36. van den Berg R, Verbist BM, Mertens BJ, van der Mey AG, van Buchem MA. Head and neck paragangliomas: Improved tumor detection using contrast-enhanced 3D time-of-flight MR angiography as compared with fat-suppressed MR imaging techniques. AJNR Am J Neuroradiol. 2004;25(5):863-70.

37. Patel SJ, Sekhar LN, Cass SP, Hirsch BE. Combined approaches for resection of extensive glomus jugulare tumors. A review of 12 cases. J Neurosurg. 1994;80(6):1026-38. http://dx.doi.org/10.3171/ jns.1994.80.6.1026

38. Witiak DG, Pensak ML. Limitations to mobilizing the intrapetrous carotid artery. Ann Otol Rhinol Laryngol. 2002;111(4):343-8. http://dx.doi.org/10.1177/000348940211100411

39. Fisch U, Pillsbury HC. Infratemporal fossa approach to lesions in the temporal bone and base of the skull. Arch Otolaryngol. 1979;105(2):99-107. http://dx.doi.org/10.1001/archotol.1979.00790140045008

40. Fisch U. Infratemporal fossa approach for glomus tumors of the temporal bone. Ann Otol Rhinol Laryngol. 1982;91(5 Pt 1):474-9. http://dx.doi.org/10.1177/000348948209100502

41. Fisch U, Fagan P, Valavanis A. The infratemporal fossa approach for the lateral skull base. Otolaryngol Clin North Am. 1984;17(3):513-52.

42. Sanna M, Piazza P, De Donato G, Menozzi R, Falcioni M. Combined endovascular-surgical management of the internal carotid artery in complex tympanojugular paragangliomas. Skull Base. 2009;19(1):26-42. http://dx. doi.org/10.1055/s-0028-1103126

43. Sanna M, Khrais T, Menozzi R, Piazza P. Surgical removal of jugular paragangliomas after stenting of the intratemporal internal carotid artery: A preliminary report. Laryngoscope. 2006;116(5):742-6. http://dx.doi.org/10.1097/01.mlg.0000205199.61105.cb 
44. Piazza P, Di Lella F, Menozzi R, Bacciu A, Sanna M. Absence of the contralateral internal carotid artery: A challenge for management of ipsilateral glomus jugulare and glomus vagale tumors. Laryngoscope. 2007;117(8):1333-7. http://dx.doi.org/10.1097/MLG.0b013e3180645d7d

45. Konishi M, Piazza P, Shin SH, Sivalingam S, Sanna M. The use of internal carotid artery stenting in management of bilateral carotid body tumors. Eur Arch Otorhinolaryngol. 2011;268(10):1535-9. http://dx.doi.org/10.1007/s00405-011-1731-7

46. Bacciu A, Prasad SC, Sist N, Rossi G, Piazza P, Sanna M. Management of the cervico-petrous internal carotid artery in class C tympanojugular paragangliomas. Head Neck. 2016;38(6):899-905. http:// dx.doi.org/10.1002/hed.24284

47. Prasad SC, Mimoune HA, D’Orazio F, Medina M, Bacciu A, Mariani-Costantini R, et al. The role of wait-and-scan and the efficacy of radiotherapy in the treatment of temporal bone paragangliomas. Otol Neurotol. 2014;35(5):922-31. http://dx.doi.org/10.1097/MAO.0000000000000386

48. Geibprasert S, Pongpech S, Armstrong D, Krings T. Dangerous extracranial-intracranial anastomoses and supply to the cranial nerves: Vessels the neurointerventionalist needs to know. AJNR Am J Neuroradiol. 2009;30(8):1459-68. http://dx.doi.org/10.3174/ajnr.A1500

49. NGS in PPGL (NGSnPPGL) Study Group, Toledo RA, Burnichon N, Cascon A, Benn DE, Bayley JP, et al. Consensus statement on next-generation-sequencing-based diagnostic testing of hereditary phaeochromocytomas and paragangliomas. Nat Rev Endocrinol. 2017;13(4):233-47. http://dx.doi. org/10.1038/nrendo.2016.185

50. Andrews KA, Ascher DB, Pires DEV, Barnes DR, Vialard L, Casey RT, et al. Tumour risks and genotypephenotype correlations associated with germline variants in succinate dehydrogenase subunit genes SDHB, SDHC and SDHD. J Med Genet. 2018;55(6):384-94.

51. Timmers HJ, Gimenez-Roqueplo AP, Mannelli M, Pacak K. Clinical aspects of SDHx-related pheochromocytoma and paraganglioma. Endocr Relat Cancer. 2009;16(2):391-400. http://dx.doi. org/10.1677/ERC-08-0284

52. Verginelli F, Perconti S, Vespa S, Schiavi F, Prasad SC, Lanuti P, et al. Paragangliomas arise through an autonomous vasculo-angio-neurogenic program inhibited by imatinib. Acta Neuropathol. 2018 May;135(5):779-98. http://dx.doi.org/10.1007/s00401-017-1799-2

53. Cama A, Verginelli F, Lotti LV, Napolitano F, Morgano A, D’Orazio A, et al. Integrative genetic, epigenetic and pathological analysis of paraganglioma reveals complex dysregulation of NOTCH signaling. Acta Neuropathol. 2013;126(4):575-94. http://dx.doi.org/10.1007/s00401-013-1165-y

54. Lack EE. Jugulotympanic paraganglioma. In: Lack EE editor. Tumors of the adrenal glands and extraadrenal paraganglia. AFIP atlas of tumor pathology. 4th series. Washington, DC: American Registry of Patholology and Armed Forces Institute of Pathology; 2007. p. 365-76.

55. Oberman HA, Holtz F, Sheffer LA, Magielski JE. Chemodectoma (nonchromaffin paragangliomas) of the head and neck. A clinicopathologic study. Cancer. 1968;21(5):838-51. http://dx.doi. org/10.1002/1097-0142(196805)21:5\%3C838::AID-CNCR2820210508\%3E3.0.CO;2-M

56. Williams MD. Paragangliomas of the head and neck: An overview from diagnosis to genetics. Head Neck Pathol. 2017;11(3):278-87. http://dx.doi.org/10.1007/s12105-017-0803-4

57. Plaza JA, Wakely PE Jr, Moran C, Fletcher CD, Suster S. Sclerosing paraganglioma: Report of 19 cases of an unusual variant of neuroendocrine tumor that may be mistaken for an aggressive malignant neoplasm. Am J Surg Pathol. 2006;30(1):7-12. http://dx.doi.org/10.1097/01.pas.0000174012.37439.c7

58. Reddy CE, Panda NK, Vaiphei K, Powari M. Pigmented vagal paraganglioma. J Laryngol Otol. 2003;117(7):584-7. http://dx.doi.org/10.1258/002221503322113102

59. Papathomas TG, Oudijk L, Persu A, Gill AJ, van Nederveen F, Tischler AS, et al. SDHB/SDHA immunohistochemistry in pheochromocytomas and paragangliomas: A multicenter interobserver variation analysis using virtual microscopy: A multinational study of the European Network for the Study of Adrenal Tumors (ENS@T). Mod Pathol. 2015 Jun;28(6):807-21. http://dx.doi.org/10.1038/ modpathol.2015.41

60. Offergeld C, Brase C, Yaremchuk S, Mader I, Rischke HC, Gläsker S, et al. Head and neck paragangliomas: Clinical and molecular genetic classification. Clinics. 2012;67(S1):19-28. http://dx.doi. org/10.6061/clinics/2012(Sup01)05 
61. Boedeker CC, Neumann HPH, Maier W, Bausch B, Schipper J, Ridder GJ. Malignant head and neck paragangliomas in SDHB mutation carriers. Otolaryngol Head Neck Surg. 2007;137:126-9. http:// dx.doi.org/10.1016/j.otohns.2007.01.015

62. Lam AK. Update on adrenal tumours in 2017 World Health Organization (WHO) of endocrine tumours. Endocr Pathol. 2017 Sep;28(3):213-27. http://dx.doi.org/10.1007/s12022-017-9484-5

63. Batsakis JG. Chemodectomas of the head and neck. In: Batsakis JG, editor. Tumours of the head and neck, clinical and pathological considerations. 2nd ed. Baltimore, MD: Williams and Wilkins, 1979. p. 280-8.

64. Brewis C, Bottrill ID, Wharton SB, Moffat DA. Metastases from glomus jugulare tumours. J Laryngol Otol. 2000 Jan;114(1):17-23. http://dx.doi.org/10.1258/0022215001903825

65. van Nederveen FH, Gaal J, Favier J, KorpershoekE, Oldenburg RA, de Bruyn EM, et al. An immunohistochemical procedure to detect patients with paraganglioma and phaeochromocytoma with germline SDHB, SDHC, or SDHD gene mutations: A retrospective and prospective analysis. Lancet Oncol. 2009 Aug;10(8):764-71. http://dx.doi.org/10.1016/S1470-2045(09)70164-0

66. Papathomas TG, de Krijger RR, Tischler AS. Paragangliomas: Update on differential diagnostic considerations, composite tumors, and recent genetic developments. Semin Diagn Pathol. 2013 Aug;30(3):207-23. http://dx.doi.org/10.1053/j.semdp.2013.06.006

67. Gill AJ, Benn DE, Chou A, Clarkson A, Muljono A, Meyer-Rochow GY, et al. Immunohistochemistry for SDHB triages genetic testing of SDHB, SDHC, and SDHD in paraganglioma-pheochromocytoma syndromes. Hum Pathol. 2010 Jun;41(6):805-14. http://dx.doi.org/10.1016/j.humpath.2009.12.005

68. Gilbert ME, Shelton C, McDonald A, Salzman KL, Harnsberger HR, Sharma PK, et al. Meningioma of the jugular foramen: Glomus jugulare mimic and surgical challenge. Laryngoscope. 2004 Jan;114(1):25-32. http://dx.doi.org/10.1097/00005537-200401000-00004

69. Salame K, Ouaknine JE, Yossipov J. Rochkind S. Paraganglioma of the pituitary fossa: Diagnosis and management. J Neurooncol. 2001;54(1):49-52. http://dx.doi.org/10.1023/A:1012535230135 
